\title{
Cued recall performance of unrelated word pairs is reduced by the presence of $A-B$, A-C items in the same list
}

\author{
DONALD ROBBINS, JAMES F. BRAY, AND JAMES R. IRVIN \\ Emory University, Atlanta, Georgia 30322
}

\begin{abstract}
Repeated pairs of words can inhibit the recall of singly presented word pairs. This intralist inhibition is observed in cued recall tasks in which one list (homogeneous) contains only singly presented word pairs and another list (mixed) contains single and repeated word pairs. Recall of singly presented word pairs is worse when there are repeated word pairs than when there are not. In the present study, instead of repeating a pair, only the stimulus term was repeated, resulting in an A-B, A-C condition. Again, recall for singly presented pairs is worse in the mixed in contrast to the homogeneous list. That is, recall for the A-B pairs is worse for lists with both A-B and A-B, A-C pairs than for lists with only A-B pairs. The data are interpreted to indicate that presumably independent items sharing no common cues do nevertheless share a common retrieval route insofar as they have a common context, namely, being members of the same list.
\end{abstract}

This study is concerned with intralist contrast effects in paired-associate learning or cued recall. The intralist contrast effect is found when a list of unrelated words contains some words that occur once ( $1 \mathrm{x}$ items) and some that occur twice ( $2 \mathrm{x}$ items). The recall of words that occurred only once is less than the recall of words in comparable lists in which all words occurred only once. This was originally found by Tulving and Hastie (1972) in free recall and they referred to the reduced recall of $1 \mathrm{x}$ items on a list containing both $1 \mathrm{x}$ and $2 \mathrm{x}$ items as an intralist inhibition effect of $1 \mathrm{x}$ items. Hastie (1975), also using a free recall task, found that this effect occurred when the subject was required to retain frequency information as well as the item itself. Most recently, Fritzen (1976) and Roediger, Stellon, and Tulving (in press) found the effect in a free recall task when frequency information was not explicitly required.

Robbins, Bray, and Irvin (1974), using a single-trial paired associate or cued recall task, also found reduced recall for $1 \mathrm{x}$ items in lists containing both $1 \mathrm{x}$ and $2 \mathrm{x}$ items when subjects were required to output both the response and the frequency of occurrence. Both Hastie (1975) and Robbins et al. (1974) concluded that the intralist contrast effect is not readily amenable to current memory conceptions. Roediger et al. (in press) suggest that strengthening some to-be-remembered items decreases the accessibility of others. In this manner, since $2 \mathrm{x}$ items are presumably "stronger" than $1 \mathrm{x}$ items, the retrieval of $2 x$ items should lead to a decrease in the probability of retrieving $1 \mathrm{x}$ items.

In the present study, another method was used to

This research was supported by a grant from the Emory University Graduate School of Arts and Sciences. Reprint requests should be sent to Donald Robbins, Department of Psychology, Emory University, Atlanta, Georgia 30322. manipulate the "strength" of an item. It should be noted that we are using the term "strength" in an operational sense, i.e., an item that has a higher level of recall than another may be said to be "stronger." A number of studies (Bruce \& Weaver, 1973; Robbins \& Bray, $1974 \mathrm{a}, \mathrm{b})$ have found that lists containing A-B, A-C items and $A-B$ control items result in higher recall of $B$ for the A-B, A-C condition in contrast to the A-B controls, termed "retroactive facilitation." Whatever the locus of this effect, A-B, A-C items, operationally at least, appear to be stronger than A-B control items with regard to the recall of $B$. As a result, lists containing both item types were presented to subjects in a singletrial cued recall task. Further, subjects were informed of the A-B, A-C conditions prior to input and at output were required to recall both responses. Although one might argue that frequency information is implicitly required, it represents another attempt to obtain the intralist contrast effect when frequency information is not explicitly required (Fritzen, 1976; Roediger et al., in press).

\section{METHOD}

\section{Design and Material}

Each subject was given one of five different types of lists; two were homogeneous lists and the remaining three were mixed lists. One homogeneous list had 18 different pairs of common English words, denoted A-B, and two primacy and recency buffers. The other homogeneous list consisted of nine pairs of $A-B, A-C$ items, with three to five pairs between the presentation of A-B and A-C. This list had two additional A-B, A-C pairs, where the presentation of the A-B pairs represented the primacy buffer and the presentation of the A-C pairs the recency buffers. There were three types of mixed lists which contained: (1) six A-B pairs and six A-B, A-C pairs, (2) six A-B pairs, three A-B, $A-C$ pairs, and three $A-B, A-B$ pairs, or (3) six $A-B, A-B$ pairs and six $A-B, A-C$ pairs. The latter list type had two additional $A-B$, $A-B$ pairs serving as the primacy and recency buffers. The former 
two mixed lists had two A-B pairs as primacy and two other A-B pairs as recency buffers.

\section{Procedure}

The subjects were run in small groups of up to five. Each small group was administered the five lists according to a 4 by 5 Latin square such that each list type occurred approximately equally often in terms of order of appearance. In addition, for approximately every other small group, the assignment of a particular word pair to a condition was changed so that each pair occurred in each condition and list type approximately equally often. The words were common English words with a Thorndike and Lorge (1944) frequency count of at least 10.

The subjects were given instructions which informed them of the nature of study and test trials. They were told of the A-B, A-C condition and told to recall both responses on test trials. The word pairs were projected on a screen at a 5-sec rate. Immediately after the presentation of a list (a study trial), the subjects were given a list of all of the stimuli from that list and were given $2 \mathrm{~min}$ for recall. The order of stimuli was random except that the buffer items were always at the end of the list. They were given a short practice list that contained A-B items, $A-B, A-B$ items, and A-B, A-C items. After the test on the practice list the five experimental lists followed. There was a 1-min break between lists.

\section{Subjects}

Fifty subjects were obtained from the introductory psychology subject pool and participated in a 25-to-30-min session.

\section{RESULTS AND DISCUSSION}

Table 1 shows the proportion recalled of responses B and $C$ for the various lists. A within-subject analysis of variance was performed comparing the $A-B, A-C$ items on the proportion of $B$ responses recalled from the three mixed lists and revealed no difference $(F<1)$. A similar result was found for response $\mathrm{C}$ for $\mathrm{A}-\mathrm{B}, \mathrm{A}-\mathrm{C}$ items from the three mixed lists $(F<1)$, as well as for the A-B items from the mixed lists $(F<1)$ and the A-B, A-B items $(F<1)$. Thus, the recall of the various item types did not appear to be affected by the other item types on the mixed lists.

However, Table 1 shows that recall of the A-B items from the mixed lists was impaired relative to the A-B homogeneous control $[\mathrm{F}(1,49)=82.32$, MSe $=2.22$, $\mathrm{p}<.001]$. This result replicates the "intralist inhibition" effect previously found in both cued and free recall tasks. Similarly, the recall for A-B, A-C items of response $\mathrm{B}$ and $\mathrm{C}$ from mixed lists was also impaired relative to that from the A-B, A-C homogeneous list $[\mathrm{F}(1,49)=27.79, \mathrm{MSe}=7.88, \mathrm{p}<.001$ for response $\mathrm{B}$ and $\mathrm{F}(1,49)=34.50, \mathrm{MSe}=6.87, \mathrm{p}<.001$ for response C]. This inhibition effect may indicate a variable that operates on the list level rather than a cue-specific level.

Table 1 also shows that on the mixed lists the recall of B for A-B, A-C items was greater than that for A-B items. Similarly, the homogeneous A-B, A-C list showed a greater proportion of $B$ responses recalled than the homogeneous A-B control list. These observations were confirmed by a within-subject 2 by 2 analysis of variance comparing the proportion of $B$ responses recalled for the two different list types (homogeneous and mixed) and two item types (A-B and A-B, A-C). This analysis revealed a significant item type effect $[F(1,49)=49.88$, $\mathrm{MSe}=5.02, \mathrm{p}<.001]$ and a significant list type effect $[\mathrm{F}(1,49)=80.31, \mathrm{MSe}=5.83, \mathrm{p}<.001]$, although the interaction was not statistically significant $(F<1)$. Thus, retroactive facilitation was found in both the mixed and homogeneous list comparisons.

We have found evidence of retroactive facilitation with both mixed and homogeneous lists. Furthermore, evidence of proactive interference was also found. Specifically, fewer C responses were recalled for A-B, A-C items relative to A-B items on both the mixed and homogeneous lists. A within-subject analysis of variance indicated a significant list type effect $[F(1,49)=9.39$, $\mathrm{MSe}=7.54, \mathrm{p}<.05]$, a significant item type effect $[\mathrm{F}(1,49)=5.81, \mathrm{MSe}=3.42, \mathrm{p}<.05]$, and a significant interaction $[\mathrm{F}(1,49)=62.69, \mathrm{MSe}=4.48, \mathrm{p}<.001]$. Furthermore, comparison of the proportions recalled of $\mathrm{B}$ and $\mathrm{C}$ revealed significantly more $\mathrm{B}$ responses recalled $[\mathrm{F}(1,49)=105.23, \mathrm{MSe}=5.59, \mathrm{p}<.001]$, for both the mixed and homogeneous lists $[F(1,49)=4.81$, MSe $=4.95, \mathrm{p}<.05]$, and a significant interaction $[\mathrm{F}(1,49)=35.28, \mathrm{MSe}=8.37, \mathrm{p}<.001]$.

The results of the present study support the Roediger et al. (in press) statement that strong items inhibit weak items and provide additional conditions under which the inhibition effect is found. Why the retrieval of "strong" items interferes with the retrieval of "weaker" items is unclear, although it does underscore the point that presumably independent items are not so independent,

Table 1

Proportion of Responses Recalled for the Various Lists

\begin{tabular}{|c|c|c|c|c|c|}
\hline \multirow[b]{2}{*}{ Item Type } & \multicolumn{3}{|c|}{ Mixed Lists } & \multirow[b]{2}{*}{ Average } & \multirow[b]{2}{*}{$\begin{array}{c}\text { Homogeneous } \\
\text { Lists }\end{array}$} \\
\hline & $\begin{array}{l}A-B \text { and } \\
A-B, A-C\end{array}$ & $\begin{array}{c}A-B, A-B \text { and } \\
A-B, A-C\end{array}$ & $\begin{array}{c}A-B \text { and } \\
A-B, A-B \text { and } \\
A-B, A-C\end{array}$ & & \\
\hline A-B & .234 & & .227 & .231 & .383 \\
\hline A-B, A-B & & .580 & .561 & .570 & \\
\hline $\mathrm{A}-\mathrm{B}, \mathrm{A}-\mathrm{C}$ & & & & & \\
\hline Recall of B & .303 & .323 & .320 & .315 & .502 \\
\hline Recall of C & .187 & .150 & .197 & .178 & .280 \\
\hline
\end{tabular}


at least when recalled. This lack of independence may suggest that items within a list are stored hierarchically under list membership, and thus may have a common retrieval cue or route (e.g., Anderson \& Bower, 1973; Petrich, 1975).

\section{REFERENCES}

ANDERson, J. R., \& Bower, G. H. Human associative memory. New York: Wiley, 1973.

Bruce, D., \& Weaver, G. E. Retroactive facilitation in short-term retention of minimally learned paired associates. Journal of Experimental Psychology, 1973, 100, 9-17.

FRITZEN, J. Intralist repetition effects in free recall. Journal of Experimental Psychology: Human Learning and Memory, 1976, 1, 756-763.

HASTIE, R. Intralist repetition in free recall: Effects of frequency attribute recall instructions. Journal of Experimental Psychology: Human Learning and Memory, 1975, 104, 3-12.
Petrich, J. A. Storage and retrieval processes in unlearning. Memory \& Cognition, 1975, 3, 63-74.

Robbins, D., \& BraY, J. F. The spacing effect and the A-B, A-C paradigm: Evidence for retroactive facilitation. Journal of Experimental Psychology, 1974, 103, 420-425. (a)

Robbins, D., \& BraY, J. F. Repetition effects and retroactive facilitation: Immediate and delayed recall performance. , Bulletin of the Psychonomic Society, 1974, 3, 347-349. (b)

Robbins, D., BRAY, J. F., \& IRWIN, J. R. Intralist contrast effects in cued recall. Journal of Experimental Psychology, 1974, 103, 150-155.

Roediger, H. L., III, Stellon, C. C., \& Tulving, E. Inhibition from part-list cues and rate of recall. Journal of Experimental Psychology: Human Learning and Memory, in press.

ThORNDIKE, E. L., \& LORGE, I. The teacher's wordbook of 30,000 words. New York: Teachers College, Columbia University, 1944.

Tulving, E., \& Hastie, R. Inhibition effects of intralist repetition in free recall. Journal of Experimental Psychology, 1972, 92, 297-304.

(Received for publication September 15, 1976.) 